\title{
AVALIAÇÃO DOS TEORES DE CÁDMIO, CHUMBO, CROMO E NÍQUEL NOS ALIMENTOS DA CESTA BÁSICA
}

ELIANE ROSE SERPE ELPO *

RENATO JOÃO SOSSELA DE FREITAS **

\begin{abstract}
Avaliou-se os teores de cádmio, chumbo, cromo e níquel nos alimentos da cesta básica adquirida no comércio de Curitiba, utilizando-se como técnica analítica a espectrofotometria de absorção atômica. Os resultados mostraram que os alimentos analisados não ultrapassaram o máximo permitido pela legislação brasileira para o cádmio e níquel, demostrando que os produtos não representam riscos de contaminação para o consumidor. Para o chumbo e cromo, alguns produtos revelaram teores acima dos limites fixados pela legislação brasileira. Os conteúdos de cádmio, chumbo, cromo e níquel nas amostras analisadas apresentaram-se dentro da faixa de variação registrada por autores de diversos países.
\end{abstract}

Elementos tóxicos estão presentes nos alimentos, em uma extensão menor ou maior, como contaminantes, devido ao aumento da industrialização. A contaminação pode surgir de fontes diversas. Assim, colheitas poderão conter variadas quantidades de contaminantes, de acordo com a natureza do solo, emprego de fertilizantes, tratamento com defensivos e

\footnotetext{
* Professora do Departamento de Saúde Comunitária, Setor de Ciências da Saúde, Universidade Federal do Paraná.

**

Professor do Departamento de Tecnologia Química, Setor de Tecnologia,
Universidade Federal do Paraná.
}

B.CEPPA, Curitiba, v. 13, n. 2, p. 71-84, jul./dez.1995 
proximidade de atividade industrial. A colheita, armazenagem, processamento e embalagem, especialmente de enlatados, além de operações domésticas, podem igualmente afetar o nivel de contaminação dos alimentos. Do mesmo modo, alguns processos, como a lavagem e o cozimento, podem provocar redução de contaminantes (10).

Sob o aspecto alimentar e com base no Comitê Misto de Peritos da FOOD AND AGRICULTURE ORGANIZATION / World Health organization (FAO/WHO) sobre Aditivos para Alimentos, para os propósitos do codex Alimentarius, "contaminante" significa qualquer substância não adicionada intencionalmente ao alimento e que é encontrada no produto como resultado da produção, manufatura, processamento, preparação, tratamento, acondicionamento, embalagem, transporte, armazenamento ou manuseio do alimento, em conseqüência de contaminação ambiental. O termo não inclui fragmentos de insetos, pêlos de roedores e outros materiais estranhos (15).

Dentre os principais metais tóxicos que podem ocorrer como contaminantes dos alimentos, e que têm merecido lugar de destaque nas pesquisas mundiais, estão $\circ$ mercúrio, ○ arsênico, o chumbo e o cádmio $(4,10,20)$.

Exceto onde há poluição, o cádmio é normalmente encontrado em baixas concentrações nos alimentos. No entanto, variações bastante amplas de concentrações foram registradas por diferentes autores (34). Para os seres humanos não expostos industrialmente, o alimento é a principal fonte de cádmio.

Estimativas de ingestão diária de cádmio, baseadas em concentrações nos alimentos e realizadas em diversos países, variam entre 25 a $60 \mu \mathrm{g} / \mathrm{dia}(28)$.

o cádmio é transportado no sangue principalmente ligado a uma proteína de baixo peso molecular, a metalotioneína. No fígado e rins, órgãos nos quais o cádmio está armazenado, este também está ligado àquela proteína. A maior parte do cádmio absorvido pelo organismo é retida, havendo pequena excreção através dos rins e intestinos (34). A excreção do cádmio na urina varia de 1 a $49 \mu \mathrm{g} / \mathrm{L}$ (3).

A ingestão de cádmio no alimento ou na bebida pode causar sintomas como náuseas, vômitos, cãimbras abdominais e dores de cabeça. Em casos severos, diarréia e choque. Cerca de 15 $\mu \mathrm{g} / \mathrm{L}$ de cádmio na água ou outras bebidas são suficientes para ocasionar esses sintomas (34).

- chumbo da água, ar e solo, através da reciclagem natural, penetra nas plantas e animais, os quais são consumidos pelo homem. O chumbo do ar é usualmente depositado sobre as folhas ou outras porções dos vegetais, e o do solo é transferido através das raízes ao caule e frutos (44). 
Alimentos processados contêm mais chumbo. DOYLE \& SPAULDING comentaram que animais, pastando próximo a rodovias e fundições, apresentaram grandes quantidades do metal em seus tecidos (13).

os alimentos constituem a principal fonte de ingestão de chumbo nas pessoas não expostas ocupacionalmente. A ingestão média diária é de $300 \mu \mathrm{g}$, com variação entre 100 e $500 \mu \mathrm{g}$ $(30)$.

No início da vida, existe pequeno depósito de chumbo no corpo. O conteúdo de chumbo do organismo aumenta com a idade (34). Segundo RELLY, estudos feitos por KEHOE et al, indicaram que cerca de $10 \%$ do chumbo ingerido é absorvido pelo trato gastrintestinal de adultos. Em crianças de três meses a oito anos, a absorção é maior, cerca de 53\% do chumbo da dieta (34). O chumbo absorvido passa à corrente sangüínea e distribui-se pelos órgãos e sistemas em função da afinidade relativa de cada tecido pelo chumbo (29). Cerca de 90\% do chumbo ingerido é excretado pela via intestinal, embora também seja eliminado pela urina, cabelo, unhas e suor (34).

os sinais comuns da intoxicação por chumbo são anemia, insônia, dor de cabeça, tontura, irritabilidade, hemorragia nas retinas, cólica estomacal, fraqueza muscular, coma, convulsões, delírio, mudança de comportamento, fadiga, perda de memória, alucinações e confusão (3).

o cromo é um dos micro-nutrientes essenciais ao homem e aos animais. Seu papel principal no organismo humano consiste na manutenção da tolerância à glicose. Deficiências do metal na dieta estão associadas com o metabolismo alterado de lipídios e da glicose, que podem resultar em doenças como a arteriosclerose e diabete (34).

o cromo é encontrado em níveis muito variáveis nos alimentos e bebidas. As quantidades presentes vão desde traços a cerca de $0,5 \mathrm{mg} / \mathrm{Kg}$. A ingestão diária é estimada entre 50 e $80 \mu \mathrm{g}$. A absorção gastrintestinal do cromo depende da sua forma química. Experimentos em animais indicam que o cromo trivalente é pobremente absorvido (34).

A excreção do cromo ocorre principalmente pela urina, embora pequenas quantidades possam ser eliminadas pelas fezes e possivelmente através da pele, unhas, leite e cabelo (5, 27, 34 ).

Estudos sobre a toxicidade do cromo, realizados em animais de laboratório, mostraram que à do cromo III é consideravelmente inferior à do cromo IV, e que aparentemente manifesta-se apenas quando a administração é feita diretamente na corrente sangüínea (5). A inalação prolongada de cromatos, na forma de pós, pode provocar irritação com hiperemia, catarro crônico, inflamação crônica dos pulmões, enfisema, bronquite crônica, faringite e broncopneumonia. A ingestão acidental ou intencional de compostos de cromo hexavalente pode causar 
irritação gastrintestinal intensa, dores epigástricas violentas, náuseas, vômitos, diarréias severas, hemorragia, colapso circulatório e morte (5).

- níquel está presente em pequenas quantidades na maioria dos solos (34) e inclui-se entre os elementos-traços de menor toxicidade ao homem por via oral, visto que é muito pouco absorvido (1).

o níquel é componente estrutural de metaloenzimas específicas ou metaloproteínas. É um co-fator bioligante, que facilita a absorção intestinal de ferro III (34). A ingestão de níquel na dieta humana está entre 0,3 e $0,6 \mathrm{mg} /$ dia (37). Sua excreção é realizada pelas fezes e em pequenas quantidades pela urina e pelo suor (42). O organismo não absorve e nem contém níquel em quantidades significantes graças ao mecanismo homeostático de controle, que somente se altera quando $\circ$ indivíduo encontra-se exposto à concentrações elevadas do metal (1).

o presente trabalho teve por objetivo avaliar os níveis de cádmio, chumbo, cromo e níquel nos alimentos da cesta básica disponíveis no mercado consumidor de curitiba, utilizando-se como técnica analítica a espectrofotometria de absorção atômica.

Os teores de cádmio, chumbo, cromo e níquel foram determinados nos treze tipos de alimentos da cesta básica, representados por três a cinco amostras de cada produto, de marcas ou procedencias diferentes, obtidos no comércio da cidade de curitiba-PR, em 1993.

o método empregado na determinação de cádmio, chumbo, cromo e níquel foi baseado nas técnicas descritas pelo Instituto Adolfo Lutz (19), pela PERKIN-ELMER (31) e por DALTON \& MALANOSKI (11).

As determinações analíticas foram realizadas em espectrofotômetro de absorção atômica com chama, modelo VARIAN AA175, de acordo com o manual do aparelho (43).

\section{RESULTADOS E DISCUSSÃO}

Os teores de cádmio, chumbo, cromo e níquel nas amostras analisadas dos alimentos da cesta básica estão representados na Tabela 1. 


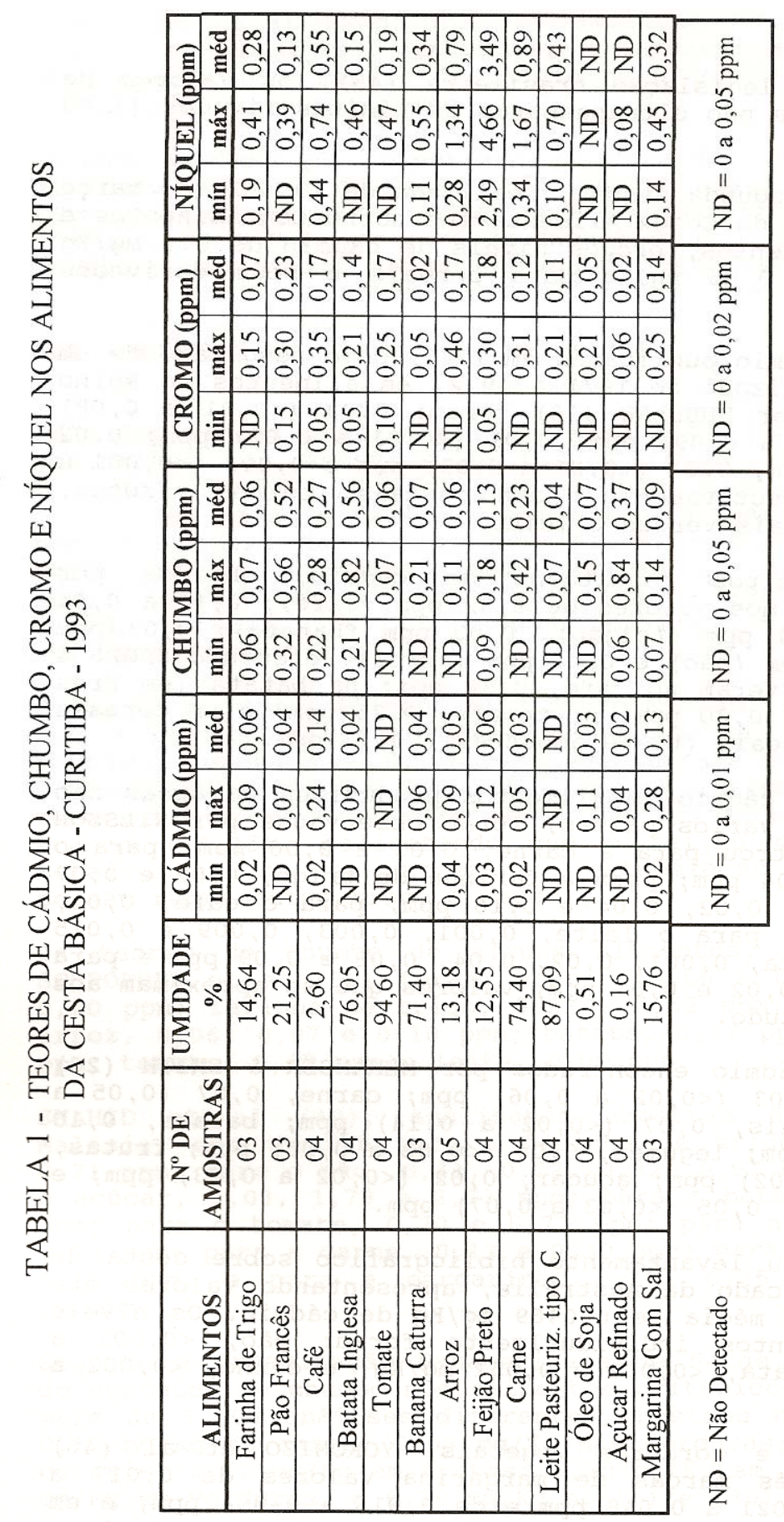

B.CEPPA, Curitiba, v. 13, n. 2, jul./dez.1995 


\subsection{CÁDMIO}

De acordo com a legislação brasileira (45), os valores de cádmio encontrados não ultrapassaram os limites fixados $(1,00$ ppm).

Na sua vigésima segunda sessão, realizada de 19 a 24 de março de 1990, o Comitê do Codex Alimentarius sobre Contaminantes e Aditivos nos Alimentos, propôs níveis de cádmio de 0,1 mg/Kg para vegetais e $0,05 \mathrm{mg} / \mathrm{Kg}$ para cereais e seus derivados (16).

os valores de cádmio publicados em 1973, como resultado de um levantamento realizado de 1971 a 1972, em alimentos no Reino Unido, citados por HUBBARD (18) foram: $0,03 \quad(<0,01$ a 0,08$)$ ppm; 0,02 (<0,01 a 0,09) ppm; $0,01 \quad(<0,01$ a 0,02$)$ ppm; 0,02 $(<0,01$ a 0,07$) \mathrm{ppm} ; 0,01(<0,01$ a 0,03$) \mathrm{ppm}$ e $0,002 \quad(<0,001$ a $0,007) \mathrm{ppm}$, respectivamente, para cereais, carnes, frutas, tubérculos, vegetais verdes e leite.

MCCAULL (25), citou resultados de cádmio, obtidos por SCHROEDER et al, nos valores de $0,32 \mathrm{ppm}$ (café); 0,10 a 0,14 ppm (leite); 0,01 ppm (feijão); 0,03 ppm (batata); 0,03 ppm (tomate); 0,22 ppm (pão) e 0,06 ppm (arroz), enquanto KROPF \& MALLINCKRODT obtiveram no café, $0,32 \mathrm{ppm}$; na batata (em três amostras), 0,18 a $0,20 \mathrm{ppm}$; no tomate, 0,25 ppm; e em cereais e produtos de cereais (treze amostras), 0,16 ppm.

Concentrações de cádmio em alimentos produzidos em áreas não contaminadas, de vários países, foram observadas por NILSSON (28). Este registrou para a carne, 0,03 e 0,06 ppm; para o arroz, 0,03 e 0,04 ppm; para a farinha de trigo, 0,02 e 0,07 ppm; para o pão, 0,02, 0,04 e 0,16 ppm; para o café, 0,01, 0,06 e 0,07 ppm; para o leite, 0,001, 0,003, 0,009 e 0,015 ppm; para a batata, 0,001, 0,02, 0,04, 0,08 e 0,09 ppm e para o tomate, 0,01, 0,02 e 0,03 ppm, valores que se aproximam aos obtidos neste estudo.

Os valores de cádmio encontrados por MÉRANGER \& SMITH (26) foram: leite, $0,03 \quad(<0,02$ a 0,06$) \mathrm{ppm}$; carne, $0,07 \quad(0,05$ a $0,08) \mathrm{ppm}$; cereais, $0,07(<0,02$ a 0,14$) \mathrm{ppm}$; batata, 0,10 $(<0,03$ a 0,22$) \mathrm{ppm}$; legumes, $0,04(<0,02$ a 0,06$) \mathrm{ppm}$; frutas, $0,02(<0,01$ a 0,02$)$ ppm; açúcar, $0,02(<0,02$ a 0,03$)$ ppm; e óleos e gorduras, $0,05(<0,03$ a 0,07$) \mathrm{ppm}$.

REILLY (34) citou levantamento bibliográfico sobre cesta de alimentos no mercado da Austrália, apresentando valores até $0,987 \mathrm{mg} / \mathrm{Kg}$, com média de $0,0469 \mathrm{mg} / \mathrm{Kg}$ de cádmio. Os níveis de alguns alimentos individualmente foram: pão, <0, 002 a $0,043 \mathrm{mg} / \mathrm{Kg}$; batata, <0,002 a $0,051 \mathrm{mg} / \mathrm{Kg}$, e carne, <0,002 a $0,028 \mathrm{mg} / \mathrm{Kg}$.

Avaliando óleos e gorduras vegetais, yokomIzo et al (46) obtiveram em três marcas de margarina valores de 0,017 a $0,036 \mathrm{ppm}$, de 0,021 a $0,048 \mathrm{ppm}$ e de 0,015 a 0,054 ppm, e em óleo de soja, 0,001 a 0,002 ppm, 0,001 a 0,003 ppm e 0,001 a $0,003 \mathrm{ppm}$. 
CORRAO et al(9) examinaram 97 amostras de leite, em três diferentes regiões (industrial, urbana e controle) e obtiveram níveis médios de cádmio na ordem de 0,027, 0,024 e $0,019 \mathrm{ppm}$, respectivamente.

CABASSI \& SOANA (6), observaram valores de cádmio no leite de diversos países, em áreas não contaminadas, de 0,001 ppm (Tchecoslováquia), de 0,009 ppm (Alemanha), de 0,003 ppm (Japão), de 0,002 ppm (Grã-Bretanha) e de 0,004 ppm (Estados Unidos), resultados que se enquadram neste estudo.

\section{2 СНUMBO}

Pela legislação brasileira $(12,45)$, estão acima dos limites admissíveis as amostras de batata (máximo 0,50 ppm), pão (máximo 0,50 ppm), leite pasteurizado tipo C (máximo 0,05 ppm), óleo de soja (máximo 0,10 ppm) e margarina (máximo 0,10 ppm) e, dentro dos niveis permitidos, a farinha de trigo e arroz (máximo 0,50 ppm), café torrado e moído (máximo 1,00 ppm), tomate (máximo 0,50 ppm), banana (máximo 0,50 ppm), feijão (máximo $0,50 \mathrm{ppm}$ ), carne (máximo $0,50 \mathrm{ppm}$ ) e açúcar refinado (máximo $2,00 \mathrm{ppm}$ ).

o Comitê do Codex Alimentarius sobre Contaminantes e Aditivos nos Alimentos propôs níveis de chumbo de 0,5 $\mathrm{mg} / \mathrm{Kg}$ para frutas e vegetais, e $0,5 \mathrm{mg} / \mathrm{Kg}$ para cereais e derivados (16). o Codex Alimentarius fixou os limites máximos de 0,1 mg/Kg para óleo de soja e margarina, e de 2,0 $\mathrm{mg} / \mathrm{Kg}$ para o açúcar branco $(14,15)$, salientando que o feijão não deve conter metais pesados, sem entretanto, estabelecer quantidades que possam representar risco à saúde (17).

Os teores de chumbo de alguns alimentos, registrados por SCHROEDER et al (36) foram: açúcar, 0,00 e 0,07 ppm; carne, $0,20 \mathrm{ppm}$; farinha de trigo, 0,23 e 0,52 ppm; pão, 0,86 ppm; arroz, 0,06, 0,07 e 0,10 ppm; batata, 0,12 ppm; feijão, 0,00 ppm; tomate, 0,02 ppm e leite, 0,00 ppm.

SHAHID et al (40), analisando amostras de alimentos da Malásia, encontraram para a farinha de trigo, 0,10, 0,20 e 0,71 ppm; para o pão, 0,41, 0,72, 0,82, 0,97 e 1,26 ppm; para o açúcar, 1,03,1,78 e 2,33 ppm; para a batata, 0,13 e 0,86 ppm; para o tomate, 0,70 e $0,73 \mathrm{ppm}$; para a banana, 0,40 e 0,74 ppm; para a carne, 0,13 e 0,30 ppm; para o leite, 0,08 e $0,19 \mathrm{ppm}$, e para a margarina, 0,10, 0,25 e 0,41 ppm de chumbo.

Segundo a Organização Panamericana de Saúde, extenso estudo do conteúdo de chumbo nos alimentos britânicos, representando mais de 3.000 análises diferentes, mostrou níveis médios de $0,17 \mathrm{mg} / \mathrm{Kg}$ na carne; $0,08 \mathrm{mg} / \mathrm{Kg}$ nas gorduras; $0,17 \mathrm{mg} / \mathrm{Kg}$ nos cereais; 0,12 $\mathrm{mg} / \mathrm{Kg}$ em frutas; $0,20 \mathrm{mg} / \mathrm{Kg}$ em tubérculos; 0,24 $\mathrm{mg} / \mathrm{Kg}$ em verduras, e $0,30 \mathrm{mg} / \mathrm{Kg}$ no leite (30). 
Há registros de conteúdos de chumbo, publicados nos Arquivos de Bromatologia (41), acusando na carne, 0, 05 a 0,74 ppm; no leite, 0,10 a $0,80 \mathrm{ppm}$, nos legumes e frutas, 0,10 a 0,24 ppm; em óleos vegetais, 0,90 a $1,25 \mathrm{ppm}$; no açúcar cristalizado, 0,50 a $0,60 \mathrm{ppm}$, e nas farinhas, 1,00 a 5,00 ppm.

Analisando 47 amostras de carne, LUCISANO et al (24) obtiveram teores de chumbo de $0,364(0,134$ a 0,825$) \mathrm{ppm} e$, registrando dados de outros autores, citaram 0,389 (0,230 a $0,607) \mathrm{ppm} ; 2,70(1,70$ a 4,20) ppm e $0,30(0,11$ a 0,50$) \mathrm{ppm}$, respectivamente, para CANTONI et al, BOLASCO et al e MONACELLI \& STACCHINI.

DALTON \& MALANOSKI (11) publicaram valores de 6,31 a 7,48 ppm e 6,93 ppm de chumbo (valor médio) para amostras de carne. SPAULDING, citado por DOYLE \& SPAULDING (13) encontrou 0,34 ppm e BOGEN, segundo KIRPATRICK \& COFFIN (22), registrou 0,42 $\mathrm{ppm}$.

- nível de chumbo anotado por CALAPAJ et al (7) para o óleo de soja, foi de 0,087 ppm. YOKOMIZo et al (46), registraram 0,04 a 0,017 ppm para o mesmo produto e analisando amostras de margarina encontraram 0,120 a 0,288 ppm. PHILAJA (32) obteve para quatro amostras de margarina <0,01, 0,04, 0, 08 e $0,28 \mathrm{ppm}$.

CORRAO et al (9), estudando três diferentes regiões de amostragem, ou seja, industrial, urbana e controle, obtiveram para o leite níveis médios de chumbo na ordem de 0,261, 0,184 e 0,076 ppm, respectivamente.

\subsection{CROMO}

Somente as amostras de farinha de trigo, banana caturra, óleo de soja e açúcar refinado ficaram dentro do limite fixado pela legislação brasileira (45), que é de 0,10 ppm.

As normas russas estabelecem limites de $0,10 \mathrm{ppm}$ para 0 leite, de $0,20 \mathrm{ppm}$ para carne, de $0,10 \mathrm{ppm}$ para frutas, de $0,20 \mathrm{ppm}$ para vegetais, de $0,40 \mathrm{ppm}$ para farinhas, e de 0,05 ppm para outros alimentos (2).

SCHROEDER et al (38), analisando os teores de cromo de vários alimentos, encontraram no leite, $0,01 \mathrm{ppm}$; na carne, 0,09 ppm; na batata, $0,00 \mathrm{ppm}$; no feijão, 0,08 ppm; no tomate, $0,01 \mathrm{ppm} ;$ na farinha de trigo, $0,00 \mathrm{ppm}$, e no arroz, $0,50 \mathrm{ppm}$.

Os valores de cromo encontrados por SCHROEDER (39) foram: $0,03 \mathrm{ppm}$ para a farinha, $0,04 \mathrm{ppm}$ para $\circ$ arroz polido, 0,12 ppm para óleos, 0,02 ppm para o açúcar branco, 0,09ppm para a carne bovina, 0,02 ppm para frutas, 0,05 ppm para legumes, 0,08 ppm para tubérculos, 0,31 ppm para grãos e cereais e 0,15 ppm para gorduras. 
Os teores médios e a faixa de variação do teor de cromo em batatas e tomate, obtidos no Reino Unido, num trabalho desenvolvido por diversos laboratórios, citado por BORDIGNON et al (5), corresponderam, respectivamente, a 0,15 (0,06 a $0,40) \mathrm{ppm}$ e $0,24(0,16$ a 0,37$) \mathrm{ppm}$, valores bem próximos aos encontrados neste estudo.

Vários dados em relação ao cromo foram registrados por CATTANEO \& CANTONI (8), como os de TOEPFER et al, que encontraram $0,57 \mathrm{ppm}$ para a carne bovina, 0,10 ppm para a banana, 0,18 ppm para a margarina, 0,26 ppm para o pão branco, 0,12 ppm para a farinha branca e 0,21 ppm para a batata. Já THOMAS et al, obtiveram $0,15(0,06$ a 0,40$)$ ppm para a batata. Os próprios autores (8), analisando amostras de carne bovina, registraram valores menores que $0,50 \mathrm{ppm}$, os quais se aproximam dos obtidos no presente trabalho.

LISK, citado por REILLY (34), registrou concentrações de cromo em diferentes classes de alimentos, como cereais (0 a $0,52 \mathrm{ppm})$, frutas $(0 \mathrm{a} 0,20 \mathrm{ppm})$, vegetais $(0 \mathrm{a} 0,36 \mathrm{ppm}) \mathrm{e}$ carnes $(0,02$ a $0,56 \mathrm{ppm})$.

Os teores de cromo encontrados por MÉRANGER \& SMITH (26), foram de $0,11(0,04$ a 0,14$) \mathrm{ppm}$ para o leite; $0,18(0,10$ a $0,27)$ ppm para a carne; $0,15(0,14$ a 0,22$)$ ppm para cereais; $0,26(0,4$ a 0,34$)$ ppm para a batata; $0,10(<0,05$ a 0,16$)$ ppm para legumes; $0,07(<0,04$ a 0,10$) \mathrm{ppm}$ para frutas; $0,33(0,20$ a 0,52$)$ ppm para o açúcar e $0,09(0,04$ a 0,19) ppm para óleos e gorduras.

Os valores médio, mínimo e máximo para a carne bovina encontrados por LUCISANO et al (24), de $0,088,0,040$ e 0,167 ppm, estão abaixo daqueles obtidos neste estudo, ao passo que outros trabalhos por eles citados registraram 0,389, 0,231 e $0,607 \mathrm{ppm} ; 2,70,1,70$ e 4,20 ppm e, 0,30, 0,11 e 0,50 ppm, valores mais elevados em relação aos deste trabalho.

\subsection{NÍQUEL}

Os valores encontrados de níquel nas amostras dos alimentos da cesta básica não ultrapassaram o limite máximo (5,00 ppm) permitido pela legislação brasileira (45).

SCHROEDER et al (38), analisando teores de níquel em vários alimentos, encontraram: $0,03 \mathrm{ppm}$ no açúcar; 0,00 ppm na carne; 0,30 e $0,54 \mathrm{ppm}$ na farinha; $1,33 \mathrm{ppm}$ no pão; 0,47 e $0,65 \mathrm{ppm}$ no arroz polido; $0,56 \mathrm{ppm}$ na batata; $1,59 \mathrm{ppm}$ no feijão; $0,03 \mathrm{ppm}$ no tomate; $0,34 \mathrm{ppm}$ na banana e 0,00 ppm no leite.

SCHETTWEIN-GSELL \& MOMMSEN-STRAUB (35) citaram dados de níquel em amostras de arroz $(0,47,0,50$ e $0,65 \mathrm{ppm})$, farinha de trigo $(0,23,0,30$ e $0,54 \mathrm{ppm})$, pão $(0,12 \mathrm{ppm})$, batata $(0,05,0,14,0,28$ e $0,56 \mathrm{ppm})$, açúcar $(0,03 \mathrm{ppm})$, feijão $(5,70 \mathrm{ppm})$, tomate $(0,62 \mathrm{ppm})$, banana $(0,34 \mathrm{ppm})$, carne $(0,06$ 
a $0,26 \mathrm{ppm})$, leite $(0,25$ a $1,30 \mathrm{ppm})$, margarina $(0,01$ a 0,62 ppm) e café $(1,00$ a 2,60 pm).

LISK, segundo REILLY (34), registrou níveis de níquel nas principais classes de alimentos, obtendo 0,00 a $6,45 \mathrm{ppm} \mathrm{em}$ cereais; 0,00 a $0,34 \mathrm{ppm}$ em frutas; 0,00 a 2,59 ppm em vegetais; 0,00 a 4,50 ppm em carnes e 0,00 a 0,03 ppm em produtos lácteos.

KIM et al (21), relataram variação nos teores de níquel em amostras de arroz polido de traços a 1,77 ppm, valores que correspondem aos resultados deste trabalho.

O conteúdo de níquel encontrado no tomate por PYATNISKAYA (33), foi $0,013 \mathrm{ppm}$, enquanto que LOPEZ et al (23) registraram valores de até 3,00 ppm. CALAPAJ et al (7), em amostras de óleo de soja, encontraram valores menores que $0,021 \mathrm{ppm}$.

Um levantamento sobre margarinas, realizado na Polônia mostrou que, enquanto muitas amostras continham entre 0,06 e $0,18 \mathrm{mg} / \mathrm{Kg}$ de níquel, uma determinada amostra apresentou 0,47 $\mathrm{mg} / \mathrm{Kg}$. Na Holanda, uma amostra de margarina acusou mais de 1,00 mg/Kg. Esses níveis, maiores que a média, foram atribuídos à remoção insuficiente de catalisador do óleo hidrogenado na fabricação de margarinas (34).

PIHLAJA (32) obteve níveis de níquel em amostras de margarina, de 0,02, 0,13 e 0,38 ppm, valores concordantes com aqueles observados no presente estudo.

Nos Arquivos de Bromatologia (41) foram registrados teores de níquel para amostras de tomate, batata, cereais e produtos derivados, e leite, de respectivamente 0,154 ppm, 0,252 ppm, 0,14 a $1,34 \mathrm{ppm}$ e 0,012 ppm.

4

\section{CONCLUSÃO}

De acordo com os resultados obtidos no presente trabalho, concluiu-se que:

Os teores de cádmio e níquel encontrados nas amostras de produtos da cesta básica adquiridas no comércio de curitiba enquadraram-se nos limites fixados pela legislação brasileira;

Dentre as amostras dos produtos analisados, a farinha de trigo, o café, o tomate, a banana caturra, o arroz, o feijão preto, a carne e o açúcar refinado não ultrapassaram os limites permitidos pela legislação brasileira para o chumbo; 
As amostras de farinha de trigo, banana caturra, óleo de soja e açúcar refinado apresentaram valores de cromo compatíveis com os limites admitidos pela legislação brasileira. Os demais produtos evidenciaram teores acima dos limites permitidos;

Os teores de chumbo obtidos para farinha de trigo, arroz, tomate, banana caturra e açúcar refinado estão de acordo com os limites fixados pelo codex Alimentarius;

Os valores de cádmio registrados para tomate, pão, farinha de trigo e arroz estiveram de acordo com a proposta apresentada pelo Comitê do Codex Alimentarius sobre contaminantes e Aditivos nos Alimentos;

os conteúdos de cádmio, chumbo, cromo e níquel nas amostras analisadas apresentaram-se dentro da faixa de variação registrada por vários de diversos países;

A concentração de metais em alimentos é de fundamental importância sob vários aspectos, principalmente quanto à saúde pública. É necessário, portanto, que seja exercido controle de qualidade, particularmente sobre aqueles alimentos de consumo diário da população brasileira.

\section{Abstract}

It was analysed the contents of cadmium, lead, chromium and nickel on food acquired in Curitiba, $\mathrm{Pr}$ (Brazil) by atomic absorption spectrophotometry. The results showed that the analysed samples were within the limits by Brazilian legislation for cadmium and nickel, demonstrating that they could be consumed. Some products presented higher level of lead and chromium than the legislation limits. The contents of cadmium, lead, chromium and nickel were within the scale of variation reported by several authors from other countries.

\section{REFERÊNCIAS BIBLIOGRÁFICAS}

1 ALEGRÍA TORÁN, A., BARBERA SAEZ, R., FARRE ROVIRA, R. Níquel: funciones en el organismo e importancia en alimentación. Alimentaria, p. 51-54, octubre, 1987.

2 AMATO, G.W. A questão do cromo em gelatina. Boletim da Sociedade Brasileira de Ciência e Tecnologia de Alimentos, Campinas, v. 1, n. 3/4, p. 179-187, 1987.

3 ANGELUCCI, E., MANTOVANI, D.M.B. Contaminantes metálicos em alimentos. Campinas : ITAL, 1981. $50 \mathrm{p}$.

4 BASSO, L.M., LASZLO, H. Ocorrência de chumbo e cádmio em fígado de aves abatidas no Rio de Janeiro. Boletim do Centro de Pesquisa e Processamento de Alimentos, v. 4, n. 1, p. 21-44, jan/jun. 1986. 
BORDIGNON, J.A., KLOSS, C.R., CHIARELLO, M.D. , WERZBITZKI, J.J., NASCIMENTO, E. O cromo em alimentos. Curitiba : Nutrimental, 1987. 55 p.

6 CABASSI, E., SOANA, S. Cádmio e ambiente. Rivista di zootecnia e veterinaria, n. 5, p. 389-398, 1975 .

7 CALAPAJ, R., CRIRICOSTA, S., SAIJA, G., BRUNO, E. Method for the determination of heavy metals in vegetable oils by graphite furnace atomic spectroscopy. Atomic Spectroscopy, v. 9, n. 4, p. 109, Jul./Aug. 1988.

8 CATTANEO, P., CANTONI, C. Il cromo negli alimenti. Industrie Alimentari, p. 487-490, 1978 .

9 CORRAO, A., CARACAPPA, S., GALLO, C. Contaminazione da metalli pesanti e composizione chimica del latte. Atti della Societa Italiana Scienze, v. 39, p. 596-599, 1985 .

10 CROSBY, N.T. Determination of metals in foods. The Analyst, v. 102, n. 1213, p. 225-268, 1977.

11 DALTON, E.F., MALANOSKI, A.J. Meat and meat products. Atomic absorption analysis of copper and lead in meat and meat products. Journal of official Analytical Chemists Association, v. 52, p. 1035-1038. 1969.

12 DINAL. Divisão Nacional de Vigilância Sanitária de Alimentos. Portaria no 16 de 13 de março de 1990. Estabelece os limites máximos de tolerância de chumbo em alimentos. Diário oficial da [República Federativa do Brasill. Brasilia, 15 de março de 1990, Seção I, p. 5436.

13 DOYLE, J.J., SPAULDING, J.E. Toxic and essential trace elements in meat: a review. Journal of Animal science, v. 47, n. 2 , p. 398-419, 1978.

14 FAO/WHO. Food Standards Programme. Codex Alimentarius Commission. Codex Standards for Sugars. Rome, 1981. p.13-17 (CAC/v. 3, 6-1981).

15 FAO/WHO. Food Standards Programme. Codex Alimentarius Commission. Contaminants. Rome, 1984. 33 p. (CAC) v. 17).

16 FAO/WHO. Food Standards Programme. Codex Commitee on food additives and contaminants. Guideline levels for cadmium and lead in food. Rome, 1989. 4 p. (CX/FAC 90/18).

17 FAO/WHO. Food Standards Programme. Codex Alimentarius Commission. Codex standard for certain pulses. Rome, 1990. 6 p. (CAC/v. 18).

18 HUBBARD, A.W. Food surveillance in the UK. Nutrition Reviews, v. 36, n. 7, p. 224-230, Jul. 1978 . 
19 INSTITUTO ADOLFO LUTZ. Normas Analíticas do Instituto Adolfo Lutz : métodos químicos e físicos para análise de alimentos. 3.ed. São Paulo, 1985. 533 p.

20 JARRET, W.D. A review of the important trace elements in dairy products. The Australian Journal of Dairy Technology, v. 34, n. 1, p. 28-34, 1979.

21 KIM, M.C., SHIM, K.H., CHUNG, D.H., CHO, K.T. Heavy metal contents in different bran layers of rice. Hanguk Nonghwa Hakhoe Chi., v. 23, n. 3, p. 141-149, 1980.

22 KIRKPATRICK, D.C., COFFIN, D.E. Cadmium, lead and mercury content of various cured meat. J. Sci. Fd. Agric., v. 24, n. 4, p. 1071-1072, 1986.

23 LOPEZ, A., WILLIANS, H.L., COOLER, F.W. Essencial elements in tomatoes and canned juice. Journal of Food Science, v. 51, n. 4, p. 1071-1072, 1986.

24 LUCISANO, A., CORTESI, M.L., DEGIOVANNI, F. Livelli di piombo, cadmio e cromo in muscolo fresco di bivini e ovini allevati in campania. Industrie Alimentari, p. 357-361, aprile 1987.

25 McCAULL, J. Building a shorter life. Environment, v. 13, n. 7, p. 3-14, 38-41, sep. 1971 .

26 MÉRANGER, J.C., SMITH, D.C. The heavy metal content of a typical canadian diet. Canadian Journal of Public Health, v. 63, p. 53-57, 1972 .

27 MERTZ, W. Chromium occurence and function in biological systems. Physiological Reviews, v. 49, n. 2, p. 163-239, Apr. 1969.

28 NILSSON, R. Some facts about cadmium. Ambio, v. 3, n. 2, p. $56-66,1974$.

29 ORGANIZACIÓN MUNDIAL DE LA SALUD. Limites de exposición profesional a los metales pesados que se recomiendam por razones de salud. Ginebra, 1980. $126 \mathrm{p}$. (Informes Técnicos, 647).

30 ORGANIZACIÓN PANAMERICANA DE LA SALUD. Riesgos del ambiente humano para salud. Washington, 1976. $356 \mathrm{p}$. (Publicación cientifica, 329).

31 PERKIN-ELMER. Analytical Methods for atomic Absorption Spectrophotometry. Connecticut, 1971. 119 p.

32 PIHLAJA, H. Determination of traces of metals in finnish margarines by the flameless atomic spectrophotometry method. Fette. Seifen. Anstrich Mittel 83 Jahrgarg, n. 8, p. 294-296, 1981 . 
33 PYATNITSKAYA, L.K. Levels of trace elements in vegetables and fruits of the Saratov region. Vop. Pitan., v. 29, n. 1, p. 83-85, 1970 .

34 REILLY, C. Metal contamination of food. London : Applied Science, 1980. 227 p.

35 SCHLETTWEIN-GSELL, D., MOMMSEN-STRAUB, S. Spurenelemente in lebensmitteln. V. nickel Internat. Z. Vit.-Ern. Forschung, v. 41, p. 429-437, 1971.

36 SCHROEDER, H.A., BALASSA, J.J. Abnormal trace metals in man: lead. J. Chron. Dis., v. 14, n. 4, p. 408-425, Oct. 1961.

37 SCHROEDER, H.A., BALASSA, J.J., TIPTON, I.H. Abnormal trace metals in man - niquel. J. Chron. Dis., v. 15, p. $51-65,1961$.

38 SCHROEDER, H.A., BALASSA, J.J., TIPTON, I.H. Abnormal trace metals in man - Chromium. J. Chron. Dis., v. 15, p. 941-964, 1962 .

39 SCHROEDER, H.A. Losses of vitamins and trace minerals resulting from processing and preservation of foods. The American Journal of Clinical Nutrition, v. 24, p. 562573, May 1971.

40 SHAHID, S.M., SIONG, T.E., HIN, C.Y. Lead content of some malaysian foodstuffs. Asean Food Journal, v. 3, n.1, p. 25-29, Mar. 1987.

41 O TEOR dos elementos minerais contidos nos alimentos. Arquivos de Bromatologia, v. 2, n. 1-2, p. 29-38, jan./jun. 1954 .

42 UNDERWOOD, E.J. Trace elements in human and animal nutrition. 4.ed. New York : Academic Press, 1977. 545 p.

43 VARIAN TECHTRON. Basic Atomic Absorption Spectroscopy. Australia : Springval, 1975. $118 \mathrm{p}$.

44 VARMA, M.M., DOTY, K.T. Environmental lead contamination. Journal of Environmental Health, v. 42, n. 2, p. 68-71. Sep./Oct. 1979 .

45 VIGILÂNCIA SANITÁRIA. Coletânea de atos em vigor pertinentes à atual legislação sanitária : de drogas, medicamentos, insumos farmacêuticos, produtos de higiene, cosméticos, perfumes e saneantes domissanitários e de portos, aeroportos e fronteiras. São Paulo : Andrei, 1979. v. 2.

46 YOKOMIZO, Y., MANTOVANI, D.M.B., ANGELUCCI, E., PASQUINELLI, S.R., DESTRO, M.T. Avaliação da contaminação de óleos e gorduras vegetais por resíduos metálicos e de pesticidas. B. Ital, Campinas, v. 21, n. 2, p. 203-238, abr./jun. 1984 . 